\title{
Clozapine Intoxication in a Patient on Chronic Use With a Short-Term Noncompliance
}

\author{
Zoha Khan $^{1}$, Emily A. Miller ${ }^{2}$, Abdullah M. Pervaiz ${ }^{1}$ \\ 1. Internal Medicine, University of Massachusetts Medical School - Baystate, Springfield, USA 2. Internal Medicine, \\ Tufts University School of Medicine, Boston, USA
}

Corresponding author: Zoha Khan, zoha.khanmd@baystatehealth.org

\begin{abstract}
Clozapine has been associated with various adverse effects at both subtherapeutic and standard doses. These adverse effects are most commonly seen during the initiation of therapy in treatment-naïve patients. However, reports of intoxication in patients with long-term use of clozapine are yet to be documented. We highlight the case of a 42 -year-old gentleman who had been on long-term clozapine use and presented with an altered mental status after being resumed on full standard doses without careful titration of clozapine after a short period of medication noncompliance. His workup in the hospital was largely unremarkable, and his presentation was attributed to the resumption of clozapine without medication titration. This is the first case to demonstrate the necessity of careful titration regardless of previous treatment history and highlights that patients should be started on clozapine at low levels to avoid the possibility of acute intoxication.
\end{abstract}

Categories: Internal Medicine, Neurology, Psychiatry

Keywords: clozapine, intoxication, chronic, psychiatry, encephalopathy

\section{Introduction}

Clozapine has been shown to cause various adverse effects including life-threatening neutropenia, agranulocytosis, and sedation at subtherapeutic as well as standard doses. These adverse effects are most commonly seen during the initiation of therapy in treatment-naïve patients. Previous cases have reported clozapine intoxication in treatment-naïve patients $[1,2]$. However, with regards to patients with long histories of clozapine use at standard doses, reports of intoxication have not been documented. Here, we present a case of clozapine intoxication in a patient with a long history of clozapine use.

Review began 07/09/2021 Review ended 07/16/2021 Published 07/23/2021

\section{(๑) Copyright 2021}

Khan et al. This is an open access article distributed under the terms of the Creative Commons Attribution License CC-BY 4.0., which permits unrestricted use, distribution, and reproduction in any medium, provided the original author and source are credited.

\section{Case Presentation}

A 42-year-old man with a past medical history of schizophrenia was found outside a behavioral health facility and appeared groggy with slurring of speech. The patient was given naloxone by emergency medical services without improvement in his symptoms and was transported to the emergency department for further evaluation. On presentation, the patient was afebrile and hemodynamically stable. He was alert and oriented to person, place, and time; however, exhibited slurred speech and an inability to stay awake despite repeated stimulation. Lab work did not show electrolyte abnormalities, leukocytosis, or a deranged thyroidstimulating hormone level (Table 1). Urine toxicology was negative for barbiturates, cannabinoids, cocaine, benzodiazepines, amphetamine, and opioids. His serum ethanol level was negative and his acetaminophen level was less than $5 \mu \mathrm{g} / \mathrm{mL}$. His urinalysis was not indicative of infection. Clozapine level was noted to be $172 \mathrm{ng} / \mathrm{mL}$ (reference range: 350-650 ng/mL). Chest X-ray showed no acute cardiopulmonary abnormality. The patient reported that he was in his usual state of health the prior night when he restarted clozapine after approximately six weeks of medication noncompliance due to the inability to see his psychiatrist for a prescription. He stated that he took $300 \mathrm{mg}$ of clozapine at the full dose the previous evening, and did not restart it with a taper. Medication history indicated that the patient had been prescribed haloperidol $5 \mathrm{mg}$ daily and clozapine $100 \mathrm{mg}$ in the morning and $300 \mathrm{mg}$ in the evening for at least three years. He denied using any opioids or alcohol. He also reported no history of recent infection, shortness of breath, chest pain, or trauma. The following day, the patient was alert and oriented to person, place, and time, and was able to converse normally with no drowsiness or somnolence. He was evaluated by the psychiatry service, and his altered mental status was attributed to the resumption of clozapine at full dose after a period of medication noncompliance. The patient was restarted on clozapine at $25 \mathrm{mg}$ twice daily with plans to increase slowly to therapeutic doses in the outpatient setting. 


\section{Cureus}

\begin{tabular}{|c|c|c|}
\hline Lab parameters & Value & Reference range \\
\hline Hemoglobin & 12.7 & 13.7-17.1 g/dL \\
\hline White blood cell count & 9.6 & $4-11 \mathrm{k} / \mathrm{mm}^{3}$ \\
\hline Sodium & 139 & 133-145 mmol/L \\
\hline Potassium & 4.2 & $3.6-5.2 \mathrm{mmol} / \mathrm{L}$ \\
\hline Glucose & 137 & 70-99 mg/dL \\
\hline Blood urea nitrogen & 15 & $6-20 \mathrm{mg} / \mathrm{dL}$ \\
\hline Creatinine & 1.2 & $0.7-1.2 \mathrm{mg} / \mathrm{dL}$ \\
\hline Calcium & 9.3 & $8.6-10.5 \mathrm{mg} / \mathrm{dL}$ \\
\hline Magnesium & 2.1 & $1.6-2.3 \mathrm{mg} / \mathrm{dL}$ \\
\hline Alkaline phosphatase & 87 & 40-129 U/L \\
\hline Aspartate aminotransferase & 14 & $0-38 \mathrm{U} / \mathrm{L}$ \\
\hline Alanine aminotransferase & 14 & $0-41 \mathrm{U} / \mathrm{L}$ \\
\hline Troponin T & $<0.01$ & $0-0.09 \mathrm{ng} / \mathrm{L}$ \\
\hline Ammonia venous & 41 & $16-60 \mu \mathrm{mol} / \mathrm{L}$ \\
\hline Thyroid-stimulating hormone & 1.57 & $0.4-4 \mathrm{mlU} / \mathrm{mL}$ \\
\hline
\end{tabular}

TABLE 1: Lab workup obtained on admission which was unremarkable for leukocytosis, hypoglycemia, or electrolyte abnormalities.

\section{Discussion}

In considering treatment for schizophrenia, both first- and second-generation antipsychotics are considered to be of equal clinical efficacy, with one exception. Clozapine, a second-generation antipsychotic, has been demonstrated to be of superior clinical efficacy in the treatment of schizophrenia. It is known to decrease mortality in treatment-resistant schizophrenia, mainly by reducing suicidal ideations [3]. However, due to its potential for severe, life-threatening side effects, clozapine is considered a second-line therapy, indicated only for patients with treatment-resistant schizophrenia/schizoaffective disorder and those with persistent self-injurious behaviors.

Clozapine has been shown to cause life-threatening neutropenia, agranulocytosis, and sedation at subtherapeutic as well as standard doses. Orthostatic hypotension, syncope, cardiac arrest, and myocarditis are additional known side effects of clozapine [4]. These adverse effects are most commonly seen during the initiation of therapy in treatment-naïve patients. As such, clozapine prescribing guidelines require doses to be titrated slowly to therapeutic levels with frequent patient monitoring. Previous cases have reported clozapine intoxication in treatment-naïve patients [1,2]. However, with regards to patients with long histories of clozapine use at standard doses with a brief period of noncompliance, reports of intoxication have not been documented. Our patient developed clozapine intoxication despite having a long history of clozapine use. The observed degree of sedation after restarting clozapine is not common in patients who have a history of previous clozapine treatment. However, we highlight the potential for adverse reactions to clozapine regardless of the duration of treatment and the necessity of tapers for all patients starting or restarting this medication.

The necessity of tapered dosing for clozapine-naïve patients is well-established. Multiple case reports have documented instances of acute intoxication in treatment-naïve patients, even at low doses

$[4,5]$. Therapeutic dosing typically requires 300-600 $\mathrm{mg}$ per day; however, patients are typically started on $12.5-25 \mathrm{mg}$ per day with gradual increases in dosages [6]. Little is known regarding clozapine intoxication in patients with previous clozapine treatment. Studies in pretreated patients have been limited to reports of intoxication in patients after large doses intended for suicide $[2,7]$. It has been suggested that previous treatment with clozapine can be protective against intoxication. Studies in animal models have supported this idea, suggesting a mechanism for clozapine tolerance [8].

Our case is unique in that the patient presented with known signs of clozapine intoxication, notably 
sedation, altered mental status, and dysarthria after taking therapeutic doses of the medication [2]. Clozapine metabolism varies widely between patients due to inherent metabolic differences, drug interactions, and patient characteristics such as age $[1,9,10]$. While evidence supports the idea of clozapine tolerance, we demonstrate the necessity of careful titration regardless of the previous treatment history. Resumption of clozapine therapy requires caution and should be restarted at low levels to avoid the possibility of acute intoxication for all patients.

\section{Conclusions}

We highlight the potential for adverse reactions to clozapine regardless of the duration of treatment and the necessity of tapers for all patients starting or restarting this medication. While evidence supports the idea of clozapine tolerance, we demonstrate the necessity of careful titration regardless of the previous treatment history. This case highlights that when prescribing or dispensing clozapine therapy greater detail regarding prior medication compliance and treatment history should be taken into account. In addition, the resumption of clozapine therapy requires caution and should be restarted at low levels to avoid the possibility of acute intoxication for all patients.

\section{Additional Information \\ Disclosures}

Human subjects: Consent was obtained or waived by all participants in this study. Conflicts of interest: In compliance with the ICMJE uniform disclosure form, all authors declare the following: Payment/services info: All authors have declared that no financial support was received from any organization for the submitted work. Financial relationships: All authors have declared that they have no financial relationships at present or within the previous three years with any organizations that might have an interest in the submitted work. Other relationships: All authors have declared that there are no other relationships or activities that could appear to have influenced the submitted work.

\section{References}

1. West S, Jeffery-Smith A, Brownlee W, Kenedi C: Covert clozapine overdose: clozapine toxicity in a naive patient. Aust N Z J Psychiatry. 2013, 47:1208-9. 10.1177/0004867413495926

2. Lebin JA, Villarreal JD, Chen BC, Hall MK: Clozapine intoxication mimicking acute stroke. Clin Pract Cases Emerg Med. 2018, 2:155-7. 10.5811/cpcem.2018.1.36734

3. Meltzer HY, Alphs L, Green AI, et al.: Clozapine treatment for suicidality in schizophrenia: International Suicide Prevention Trial (InterSePT). Arch Gen Psychiatry. 2003, 60:82-91. 10.1001/archpsyc.60.1.82

4. Miller DD: Review and management of clozapine side effects . J Clin Psychiatry. 2000, 61 Suppl 8:14-7.

5. Krämer I, Rauber-Lüthy C, Kupferschmidt H, Krähenbühl S, Ceschi A: Minimal dose for severe poisoning and influencing factors in acute human clozapine intoxication: a 13-year retrospective study. Clin Neuropharmacol. 2010, 33:230-4. 10.1097/WNF.0b013e3181f0ec55

6. VanderZwaag C, McGee M, McEvoy JP, Freudenreich O, Wilson WH, Cooper TB: Response of patients with treatment-refractory schizophrenia to clozapine within three serum level ranges. Am J Psychiatry. 1996, 153:1579-84. 10.1176/ajp.153.12.1579

7. Thomas L, Pollak PT: Delayed recovery associated with persistent serum concentrations after clozapine overdose. J Emerg Med. 2003, 25:61-6. 10.1016/s0736-4679(03)00130-6

8. Feng M, Gao J, Sui N, Li M: Effects of central activation of serotonin 5-HT2A/2C or dopamine D 2/3 receptors on the acute and repeated effects of clozapine in the conditioned avoidance response test. Psychopharmacology (Berl). 2015, 232:1219-30. 10.1007/s00213-014-3756-2

9. Jann MW, Grimsley SR, Gray EC, Chang WH: Pharmacokinetics and pharmacodynamics of clozapine. Clin Pharmacokinet. 1993, 24:161-76. 10.2165/00003088-199324020-00005

10. Prior TI, Baker GB: Interactions between the cytochrome P450 system and the second-generation antipsychotics. J Psychiatry Neurosci. 2003, 28:99-112. 